\title{
Relation of neutrophil alkaline phosphatase activity to Fc-IgG receptor development in human blood and bone marrow
}

\author{
CS SCOTT, RJ CORDINGLEY, BE ROBERTS, AG BYNOE, D HOUGH \\ From the Department of Haematology, Regional Radiotherapy Centre, Cookridge Hospital, Leeds, and the \\ Department of Biochemistry, University of Bath, Claverton Down, Bath BA2 7AY
}

SUMMARY A possible correlation between Fc-IgG receptor expression and neutrophil alkaline phosphatase (NAP) activity was investigated in relation to maturation of granulocytes in human peripheral blood and bone marrow. NAP activity was studied in bone marrow from patients with normal peripheral blood NAP scores (20-100) and compared with those with high NAP scores. Results indicate that NAP activity is confined to segmented neutrophils (SN) in marrow and peripheral blood except when peripheral NAP activity is abnormally high. There is a normal increase of approximately $60 \%$ in mean NAP scores of peripheral blood compared to marrow SN.

Granulocyte Fc-IgG receptor activity, known to increase with maturation, was studied in relation to NAP activity. A combined assay using a rosetting technique with ox-erythrocyte (oxE) antibody-IgG and subsequent NAP cytochemistry was used. Receptor expression was found to be virtually complete in normal granulocytic maturation before the appearance of detectable NAP activity. This was supported by findings in chronic myeloid leukaemia where no cases of low Fc receptor activity were found despite NAP scores of $<5$. The significance of these findings is discussed in the light of current concepts of the control of NAP activity.

The assessment of neutrophil alkaline phosphatase (NAP) activity is recognised as being of value in the differential diagnosis and characterisation of conditions associated with changes in neutrophil kinetics and in the evaluation of granulocytic disorders. However, the relation between NAP activity and neutrophil maturation is controversial with some favouring the view that NAP activity is directly related to neutrophil age ${ }^{1-3}$ while others suggest the reverse, with NAP activity decreasing with maturity..$^{4-7}$ Thus it was considered worthwhile to compare marrow neutrophil NAP scores in normals and marrows from patients with a high peripheral blood NAP score. In a previous study it was shown that the synthesis and expression of granulocyte membrane receptors for $\operatorname{IgG}(\mathrm{Fc})$ is primarily associated with the terminal stages of neutrophil maturation and segmentation..$^{8}$ In view of this apparent relationship between receptor expression and neutrophil maturity, the second part of this study set out to compare Fc-IgG receptor expression and NAP activities of individual peripheral blood neutrophils in a combined assay. Normal subjects and patients with chronic myeloid leukaemia, with low NAP scores, were studied.

\section{Material and methods}

PREPARATION OF IgG ANTI-OX ERYTHROCYTE (oxE) ANTIBODIES

Immunoglobulin $G$ anti-oxE were prepared by intravenous inoculation of rabbits with boiled oxE stroma.? The whole serum reagents obtained by bleeding were decomplemented by heat treatment. IgG was partially purified by ACA 34 (LKB) gel filtration and the IgM fractions discarded. The IgG fractions were affinity-purified on Sepharoseprotein A (Pharmacia), eluted with $1 M$ acetic acid and passed through Sephadex G25 (Pharmacia) into $0 \cdot 1 M$ phosphate buffer $\mathrm{pH} 7 \cdot 0$. The concentration of IgG was determined by measurement of specific absorbance at $280 \mathrm{~nm}$. 
PREPARATION OF SENSITISED oxE

Washed oxE were resuspended to $2 \%$ in Hanks' medium (Flow laboratories) and incubated at $37^{\circ} \mathrm{C}$ with an equal volume of IgG antibody, the concentration of which was varied to achieve a range of sensitisations. After incubation the oxE antibodyIgG were washed once in Hanks' and resuspended to $1 \%$ for use in Hanks' supplemented with $0.1 \%$ gelatin. The range of oxE antibody sensitisations, 1:80 to $1: 640$ with this particular IgG antibody, were designed to show maximum changes in the percentage rosette-forming neutrophils with small variations in the level of IgG sensitisation thus making the system sensitive to minor differences in neutrophil Fc-IgG receptor affinities.

\section{DEMONSTRATION OF NEUTROPHIL FC-IgG} RECEPTORS

Blood for testing was anticoagulated with EDTA and mixed with a 1:5 volume of Plasmagel (Uniscience). After erythrocyte sedimentation, the leucocyte-rich supernatant was washed twice in Hanks' and resuspended to $1.6 \times 10^{6} \mathrm{cells} / \mathrm{ml}$ in Hanks'-gelatin. For the rosette assay equal volumes of the appropriate oxE antibody and leucocyte suspension were mixed, incubated at $4^{\circ} \mathrm{C}$ for $5 \mathrm{~min}$ and then pelleted by centrifugation at $100 \mathrm{~g}$ for $3 \mathrm{~min}$. After further incubation at $4^{\circ} \mathrm{C}$ for $30 \mathrm{~min}$, the cell mixture was resuspended in cold Hanks' and cytocentrifuged on to glass slides. Slides were stained by Romanowsky or NAP and examined for neutrophil rosette formation and NAP activity.

\section{DEMONSTRATION OF NAP}

Freshly made peripheral blood/marrow smears or cytocentrifuged rosette preparations were fixed in formol-methanol and stained for NAP by a modification of the method of Rutenberg. ${ }^{10}$ After incubation in a medium containing naptthol AS-MX phosphate (Sigma) and fast blue BBN (BDH) for $45 \mathrm{~min}$, the films were dried, post-fixed in formaldehyde vapour and counterstained in $0.6 \%$ neutral red. NAP scores were assessed in a conventional manner. ${ }^{11}$

Blood was taken into EDTA to prevent low level complement activation and possible stearic blocking of IgG receptors. ${ }^{1213}$ Paired studies (data not shown) of NAP activities on EDTA-anticoagulated and capillary samples showed no significant differences when, as in this investigation, exposure to EDTA was less than $30 \mathrm{~min}$.

Samples for study of NAP activity in developing granulocytes were obtained from 13 patients; five with no haematological abnormalities, four megaloblastic anaemias of mild to intermediate severity and four cases of primary myeloid dysplasia, in whom the absolute peripheral neutrophil counts and the peripheral blood NAP scores were within normal limits. Comparisons were made with 13 marrows from patients with raised peripheral NAP scores; these included patients with myeloproliferative disorders, myelodysplastic conditions and one patient (ED) in whom no cause was found.

For the correlation of NAP and Fc receptor activities, blood samples were taken into EDTA from 18 normal volunteers. Neutrophils were then examined in a combined assay and the NAP scores of individual neutrophils were related to their ability to form IgG rosettes at each level of IgG sensitisation. Results from these investigations and previously published studies $^{814}$ were contrasted with those from seven cases of $\mathrm{Ph}^{\prime}$ positive $\mathrm{CML}$ in which the NAP scores were $<5$.

\section{Results}

NAP ACTIVITIES IN DEVELOPING NEUTROPHILSCORRELATION WITH MORPHOLOGY

NAP activities in non-segmented neutrophils (NSN) and segmented neutrophils (SN) from the "normal" group of bone marrows show that NAP activity increases with maturation-marrow NSN show no significant activity, marrow $\mathrm{SN}$ have a mean score o 42 and peripheral blood neutrophils a mean of 66 (Figure). Thus bone marrow SN NAP scores are approximately $2 / 3$ of that seen in peripheral blood. Furthermore, the increase in peripheral NAP activity, compared to that of marrow $\mathrm{SN}$, is primarily due to a relative decrease in the number of NAPnegative cells. The mean percentages of cells in each NAP category were:

\begin{tabular}{lllcl}
\hline & NAP O & NAP 1 & NAP 2 & NAP 3 \\
\hline marrow SN & 67 & 24 & 7 & 5 \\
peripheral neutrophils & 47 & 39 & 12 & 5 \\
\hline
\end{tabular}

In patients with raised peripheral blood NAP scores, significant NAP activities could also be demonstrated in marrow NSN (Table 1).

NAP ACTIVITIES IN NORMAL PERIPHERAL BLOOD NEUTROPHILS-CORRELATION WITH Fc-IgG RECEPTOR ACTIVITIES (Table 2)

Fc-IgG receptor activities of peripheral neutrophils, as assessed by their ability to bind $\mathrm{OE}$ antibody at different levels of IgG sensitisation, are shown in Table 2. Results are analysed for three subpopulations of neutrophils defined by their NAP scores $(0$, 1 and 2 -insufficient cells were seen with scores of 3 ). There is some difference at the $1: 80$ IgG sensitisation $(p<0.05)$ between neutrophils with NAP 


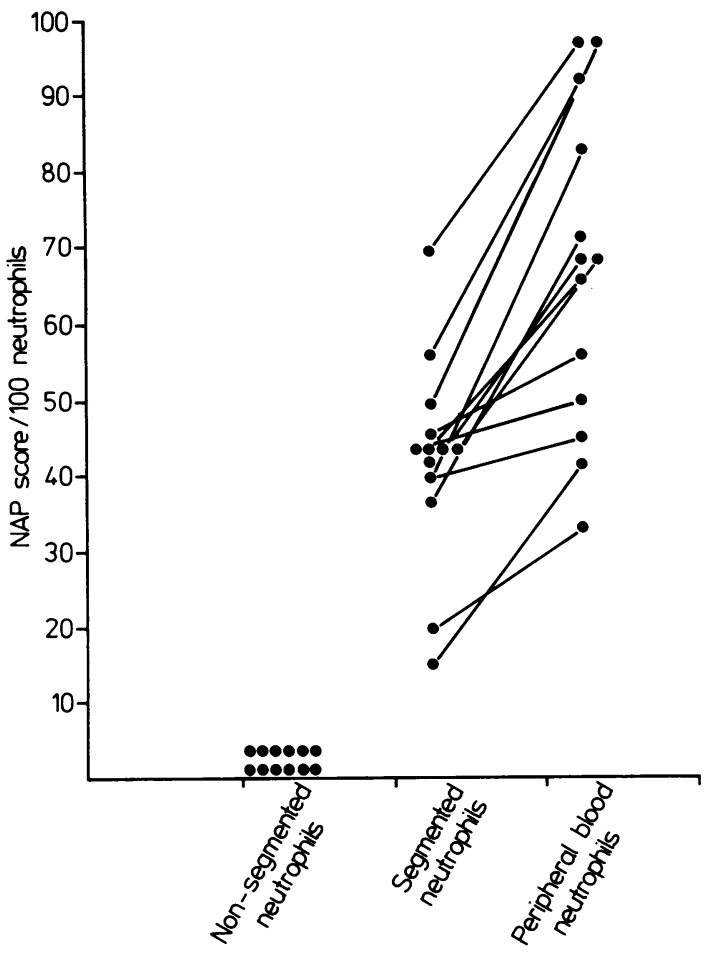

Expression of alkaline phosphatase activity in developing neutrophils. Results are shown as the NAP scores of marrow non-segmented neutrophils, and peripheral blood neutrophils.

reactions of 0 and 1 but a much greater difference is seen between scores of 0 and $2(p<0.002)$. There is no significant difference in receptor activity in the other IgG sensitisations used. The results therefore indicate that $F c$ receptor expression is virtually complete prior to the emergence of NAP activity which occurs at a late stage in the granulocyte maturation sequence. However there is a small number (approximately 5\%) of normal peripheral blood segmented neutrophils in which Fc-IgG receptor
Table 1 Bone marrow non-segmented (NSN) and segmented neutrophil (SN) alkaline phosphatase activities in patients with increased peripheral blood NAP scores

\begin{tabular}{|c|c|c|c|}
\hline \multirow[t]{2}{*}{ Patient } & \multicolumn{2}{|c|}{ Bone marrow NAP scores } & \multirow{2}{*}{$\begin{array}{l}\text { Peripheral blood } \\
\text { NAP scores }\end{array}$} \\
\hline & $N S N$ & $S N$ & \\
\hline $\begin{array}{l}\text { ES } \\
\text { JM } \\
\text { AD (1) } \\
\text { ED } \\
\text { DE } \\
\text { CC } \\
\text { WS } \\
\text { JR } \\
\text { FB } \\
\text { AJ } \\
\text { AH } \\
\text { AD (2) } \\
\text { EH }\end{array}$ & $\begin{array}{r}16 \\
<5 \\
22 \\
<5 \\
<5 \\
<5 \\
54 \\
8 \\
<5 \\
<5 \\
20 \\
24 \\
<5\end{array}$ & $\begin{array}{r}122 \\
141 \\
173 \\
104 \\
106 \\
66 \\
240 \\
119 \\
70 \\
72 \\
112 \\
192 \\
83\end{array}$ & $\begin{array}{l}198 \\
162 \\
188 \\
122 \\
110 \\
132 \\
239 \\
118 \\
105 \\
130 \\
152 \\
194 \\
133\end{array}$ \\
\hline
\end{tabular}

expression appears incomplete and in which there is no detectable NAP.

GRANULOCYTE RECEPTORS IN CML

Examination of the maturation-related expression of granulocyte $\mathrm{IgG}$ receptors ${ }^{8}$ in CML showed that all cases examined had essentially normal receptor activity on post-mitotic granulocytes (data not shown). Thus decreased receptor activity was not found despite peripheral blood NAP scores of $<5$.

\section{Discussion}

This investigation has compared the expression of NAP with classical morphological features and to the maturation-linked development of Fc-IgG receptors. Morphological comparisons made here indicate that NAP activity is primarily associated with segmented neutrophils and that NAP activities in non-segmented marrow neutrophils are very low. Interpretation of these findings is difficult in that marrow and peripheral blood segmented neutrophils have similar morphological features. This is also complicated because marrow NAP-positive neutrophils could represent either the maturation or

Table 2 Relation between NAP activity and the ability to bind oxE antibody-IgG at different levels of $\operatorname{Ig} G$ sensitisation. Results are shown as the mean percentage rosette-forming neutrophils at each concentration of sensitising IgG anti-oxE together with the standard error of the mean (SEM)

\begin{tabular}{|c|c|c|c|c|c|}
\hline & & \multicolumn{4}{|c|}{ Rabbit IgG anti-oxE dilution } \\
\hline & & $1: 80$ & $1: 160$ & $1: 320$ & $1: 640$ \\
\hline $\begin{array}{l}\text { Data for all neutrophils } \\
\text { Neutrophils with NAP } 0 \text { reactions } \\
\text { Neutrophils with NAP } 1 \text { reactions } \\
\text { Neutrophils with NAP } 2 \text { reactions }\end{array}$ & $\begin{array}{l}\text { mean\% } \\
\text { SEM } \\
\text { mean\% } \\
\text { SEM } \\
\text { mean\% } \\
\text { SEM } \\
\text { mean\% } \\
\text { SEM }\end{array}$ & $\begin{array}{l}86 \\
2 \cdot 4 \\
78 \\
2 \cdot 9 \\
86 \\
2 \cdot 8 \\
86 \\
5 \cdot 2\end{array}$ & $\begin{array}{l}61 \\
3 \cdot 3 \\
57 \\
3 \cdot 4 \\
59 \\
4 \cdot 3 \\
56 \\
6 \cdot 4\end{array}$ & $\begin{array}{l}22 \\
1 \cdot 3 \\
21 \\
3 \cdot 6 \\
17 \\
2 \cdot 9 \\
18 \\
4 \cdot 5\end{array}$ & $\begin{array}{l}10 \\
2 \cdot 9 \\
8 \\
2 \cdot 4 \\
11 \\
3 \cdot 9 \\
12 \\
2 \cdot 4\end{array}$ \\
\hline
\end{tabular}


storage compartments and that peripheral neutrophil populations consist of cells in transit to and from various body pools. Furthermore it is not possible to assess the affect of peripheral blood contamination in marrow aspirates even though the relative marrow and peripheral blood cell counts mean that the contamination would have to be marked in order to affect marrow granulocyte distributions.

The second part of the study in which NAP activity was compared to Fc-IgG activities revealed that the expression of cytochemically demonstrable NAP is a late event in granulocyte differentiation and that Fc-IgG receptor synthesis appears to be complete prior to the expressions of this enzyme, with the exception of a small population of peripheral neutrophils. As neutrophil recirculation appears to be insignificant, the possibility that NAP-positive bone marrow cells are those which have been exposed to extracellular factors restricted to the peripheral circulation is unlikely. While it is possible that these factors are able to modulate marrow granulocytes, the appearance of alkaline phosphatase activity is still only confined to segmented cells and it is probable that enzyme activation requires an intracellular component ${ }^{15}$ such as a cofactor or modifier which itself may be linked to the level of functional maturation. It is of interest that significant amounts of NAP activity could also be demonstrated in marrow NSN in cases where the peripheral NAP score was markedly increased. This suggests either some degree of asynchronous development or an alteration in the balance of internal or external factors which control cellular NAP expression.

A mechanism whereby NAP activity is modulated by hormones, ${ }^{16}$ particularly corticosteroids, ${ }^{17}$ or the presence of a controlling depressor-repressor system $^{18}$ is further supported by findings that NAPnegative neutrophils in CML may become positive when incubated in normal donor plasma ${ }^{1920}$ and show significant increases in NAP activity after transfusion into neutropenic patients. ${ }^{21}$ Examination of seven cases of CML with low NAP scores in this study shows the granulocyte Fc-IgG receptor activities to be normal. The indications, therefore, are that low NAP scores in CML may be due to a terminal differentiation block at the post-Fc receptor development stage or a defect or imbalance of the extracellular mechanisms which exert an influence on NAP expression.

In conclusion, it is reasonable to suggest that the results of this study, together with those of others, indicate that the expression of Fc-IgG and NAP activities are under separate control. In normal development NAP is a feature of terminal neutrophil maturation with receptor synthesis stages being largely completed prior to the emergence of

\section{demonstrable NAP.}

We would like to thank the clinical haematologists of Leeds Western District for their support and $\mathrm{Mr}$ A Cahill for his technical assistance.

\section{References}

1 Trubowitz S, Feldman D, Benante C, Hunt UM. The alkaline phosphatase content of the human polymorphonuclear leukocyte in blood and marrow. Am J Clin Pathol 1959;31:483-6.

${ }^{2}$ Bondue H, Machin D, Strykmans PA. The leukocyte alkaline phosphatase activity in mature neutrophils of different ages. Scand J Haematol 1980;24:51-6.

${ }^{3}$ Pederson B, Hayhoe FGJ. Relation between phagocytic activity and alkaline phosphatase content of neutrophils in chronic myeloid leukaemia. Br J Haematol 1978;31:371-9.

${ }^{4}$ Williams DM, Lampert IA, Evans DJ. A comparison using quantitative cytochemistry between leucocyte alkaline phosphatase levels in the bone marrow and blood of the rat. Br J Haematol 1978;40: 119-24.

${ }^{5}$ Williams DM. Leucocyte alkaline phosphatase as a marker of cell maturity; a quantitative, cytochemical and autoradiographic study. Br J Haematol 1978;31:371-9.

- Mishler JM, Williams DM. Alkaline phosphatase as a marker of maturity in human neutrophils. J Clin Pathol 1980;33:555-61.

7 Spiers ASD, Liew A, Baikie AG. Neutrophil alkaline phosphatase score in chronic granulocytic leukaemia; effects of splenectomy and antileukaemic drugs. J Clin Pathol 1975;28:517-23.

${ }^{8}$ Scott CS. Maturation-linked expression of the $\mathrm{Fc}(\mathrm{IgG})$ receptor on developing human bone marrow and peripheral blood granulocytes. Clin Exp Immunol 1979;38:300-5.

9 Kabat EA, Mayer MM. Complement and complement fixation In: Kabat EA, Mayer MM, eds. Experimental immunochemi@ try Springfield, Illinois: Charles C Thomas, 1961:132-240.

${ }^{10}$ Rutenberg AM, Rosales CL, Bennett JM. An improved histochemical method for the demonstration of leukocyte alkaline phosphatase activity in clinical application. $J$ Lab Clin Med 1965;65:698-703.

"Hayhoe FGJ, Quaglino D. Cytochemical demonstration and measurement of leukocyte alkaline phosphatase activity in normal and pathological states by a modified azo-dye technique. Br J Haematol 1958;4:375-82.

${ }^{12}$ Kitamura $H$, Teshima $H$, Day NK. The presence of active $\mathrm{Cl}$ (C1) on peripheral human lymphocytes. Vox Sang 1978;35:197-202.

13 Wilson AB, Kannski A, Coombs RRA. Artefactural variations in the $B$ and $T$ subpopulations of rabbit blood lymphocytes depending on method of isolation, and blocking of C3 receptors due to in-vitro activation of complement. J Immunol Methods 1978;24:201-6.

${ }^{14}$ Scott CS, Ainley MJ. Granulocyte IgG and complement receptors; recent insights and applications. Med Lab Sci 1981;38:395-403.

15 Cox RP, Elson NA, Tu S, Griffin MJ. Hormonal induction of alkaline phosphatase activity by an increased catalytic efficiency of the enzyme. J Mol Biol 1971;58:197-203.

16 Valentine WN, Follette JH, Hardin EB, Beck WS, Lawrence JS. Studies on leukocyte alkaline phosphatase activity; relation to stress and pituitary-adrenal activity. $J$ Lab Clin Med 1954;44:219-24.

${ }^{17}$ Hayhoe FGJ, Quaglino D. Phosphatases. In: Hayhoe FGJ, Quaglino D, eds. Haematological cytochemistry Edinburgh: Churchill-Livingstone, 1980:105-45.

18 Rosen RB, Teplitz RL. Chronic granulocytic leukaemia complicated by ulcerative colitis; elevated leukocyte alkaline phosphatase and possible modifier gene deletion. Blood 1968;26:148-54. 
${ }^{19}$ Hellmann A, Goldman JM. Alkaline phosphatase activity of chronic granulocytic leukaemia neutrophils in agar culture. Scand J Haematol 1980;24:237-42.

${ }^{20}$ Chikkapa G, Boeker WR, Borner G, et al. Return of alkaline phosphatase in chronic myelocytic cells in diffusion chamber cultures. Proc Soc Exp Biol Med 1973;143:212-8.

${ }^{21}$ Rustin GJS, Goldman JM, McCarthy D, Mees S, Peters TJ. An extrinsic factor controls neutrophil alkaline phosphatase synthesis in chronic granulocytic leukaemia. Br J Haematol 1980;45:381-7.

Requests for reprints to: Dr CS Scott, Department of Haematology, Regional Radiotherapy Centre, Cookridge Hospital, Leeds LS16 6QB, England. 